\title{
THE PERVASIVENESS OF METAPHOR IN THE LANGUAGE OF ECONOMICS
}

\author{
Gabriela Telibașa \\ "Vasile Alecsandri” University of Bacău, \\ gabriela_andrioai@yahoo.com
}

\begin{abstract}
Nowadays, metaphors can be seen in a totally new light, exceeding their primary function of being used only as ornamental tropes and becoming powerful instruments of expressiveness. They are active in the development of a conceptual framework for representing new ideas, as well as in providing new meaning. With their help, readers gain a more precise understanding of the terminology and scientific concepts and therefore, contribute to a greater accuracy in the use of language. Given their pervasiveness, language becomes less abstract and more manageable in concretising, objectivising or even humanising concepts. Economy related topics are part of our everyday's language. Having a close relationship with human beings and human society, the field of Economics becomes a rich linguistic domain which, if explored, proves to be very productive in offering semantic extension. Applying conceptual terminology to corpus material we shall try to identify, classify and gather information with specific interest in metaphors that belong to the field of Economics.
\end{abstract}

\section{Keywords}

economy; conceptual metaphors; structural metaphors; orientational metaphors; ontological metaphors; source domain; target domain

\section{JEL Classification}

Z 19

\section{Introduction}

Different definitions have been given to metaphors along time but, what is important to notice is that theoreticians have come to the conclusion that metaphors can be seen in a totally new light, exceeding their primary function of being used only as ornamental tropes and becoming powerful instruments of expressiveness.

The contemporary theories have criticized the traditional conception about metaphor and took into consideration the trope's ornamental function, as well as the relationship between the metaphor and the concept.

Nowadays, we can talk about the pervasiveness of metaphor in everyday life, not only in language (as classical theories demonstrate) but also in thought and action. This new perspective, developed by George Lakoff and Mark Johnson in their book Metaphors We Live by, had a tremendously positive impact on the study of metaphor. According to their cognitive view of metaphor, language is filled with a large number of metaphorical expressions that are not frozen, but which reflect large-scale metaphorical systems. Thus, in order to understand the nature of language we have to look at our conceptual world and see how it has shaped signs because language covers only a part of the world of concepts which humans have or may have.

In conceptual theories, metaphor is defined as understanding one conceptual domain in terms of another conceptual domain, a domain that can be any coherent organization of experience. The conceptual domain from which we draw metaphorical expressions 
corresponds to the source domain; and the conceptual domain that we try to understand corresponds to the target domain. Metaphorical connections arise from the perception of correlations between different domains such as life, living organisms (plants, tress, flowers, etc.), food (solid or liquid substances), Economics, Information Technology, Engineering, Sports, etc., but they can also make us see new associations or they can make us attribute new structures or properties to objects, concepts and situations. This is done by means of the mapping of a source domain onto a target domain. With the cognitive view, metaphor becomes a matter of conceptual mapping from a source domain (the domain that is mapped) to a target domain (the domain onto which it is mapped), the metaphorical expressions being the primary exemplars of such conceptual mappings. Thus, through mapping we understand a systematic set of correspondences that exist between the constituent elements of the source and the target domain. To know a conceptual metaphor is to know the set of mappings that applies to a given source-target pairing.

\section{Case Study}

Our case study aims at applying conceptual terminology to corpus material trying to identify, classify and gather information with specific interest in metaphors that belong to the field of Economics. Nowadays, Economics plays a very important role in our life because we are interested in how we get our living. Prices are continually increasing, industry is also changing, the government makes efforts to stabilize economies and prevent inflation. Economics is about the everyday things of life thus, it is normal that terms such as budget, labour, market, stock exchange, bills, insurance, management, financial deficit, capital, money, payment, banks, etc., to be familiar to people. Having such a close relationship with the human society, the field of Economics becomes a rich linguistic domain which can be explored. Metaphor, at its turn, is a concept with multidisciplinary implications and can be found in every aspect of human thought. It becomes obvious that in trying to perceive the world of Economics, metaphor is indispensable in defining Economic problems and principles. It sometimes happens that, given their daily usage, people are no longer conscious of the metaphorical structure on which their sentences base. In such cases, they lose their metaphorical value and become dead metaphors. This is the case of the following example:

Economy is a car, not $a$ body. (BNC)

The interpretation of this metaphor leads to a new meaning but it is not that rich as other examples we are going to explain. A car is a more familiar concrete concept than the concept of Economy. When comparing Economy with an object such as a car, we understand that Economy, as a whole, can work as smoothly as a car. This meaning may give us the impression that Economy is as predictable as a machine or that it may be kept under control exactly the way people control the machines they are working with. Since a metaphor relies on the literal use of a word just to indicate that the speaker wants to communicate something other than the literal meaning, we believe that the negation has been used here, only to create a contrast between two conceptual metaphors. In fact, the negation is trying to hide the features the metaphor is trying to highlight. In the case of "Economy is not a body", the meaning implied is that, in opposition to cars, human bodies are fragile.

Applying the cognitive theory, this metaphor is of the type A is B and belongs to the conceptual metaphor: ECONOMY IS A MACHINE/MECHANISM. According to Lakoff and Johnson there are three categories of conceptual metaphors: structural, orientational and ontological. Such metaphors activate at least two domains of knowledge by replacing the employed domain onto the source domain. While interpreting conceptual metaphors, it is important to have in mind the possibility for the three categories to overlap. Our example belongs to structural metaphors. Within this 
type, conceptual metaphors refer to abstract metaphorical systems in which an entire (abstract) complex mental "concept is metaphorically structured in terms of another" (usually more concrete) concept. Structural metaphors "allow us to use one highly structured and clearly delineated concept to structure another." Such metaphors activate at least two domains of knowledge by replacing the employed domain onto the source domain. (George Lakoff and Mark Johnson, 1980) In our case Economy is the abstract concept which is explained in terms of the more concrete concept of machines. Usually more than one abstract knowledge domain is structured in terms of the same basic source domain (the abstract domains being partially structured in terms of more concrete domains).

The machine as a source domain is metaphorically applied to understand the abstract concepts of Economy. In expressing the metaphor in written terms, the more abstract domain (ECONOMY) comes first; a form of the verb to be immediately follows it, while the concrete domain (BODY, FOOD, PLANT, LIQUID, etc.) is placed at the end. All the constituting parts of the metaphor are written in uppercase letters.

Other examples illustrating the conceptual metaphor ECONOMY IS A MACHINE are represented by the following examples:

The funds received are the fuel needed to make this business work. (BNC) A car won't start without fuel. Here, funds are considered very important for the future of the business. Another similar example of this type is:

An aid programme was established to oil the wheels of economic reform in the region. (http://dictionary.cambridge.org/dictionary/british/oil-the-wheels accessed on 20 March 2015.) By "oiling the wheels" the reform will work smoothly.

Wise market transactions can contribute to the well functioning of our company. (BNC) Without good transactions a company won't resist on the market.

Your plan is the engine needed to make our business work. (BNC) The engine is the most important part of a car without it, a car wouldn't start. A good plan can make a business work.

This is the capital needed to fix your business. (BNC) Machines break, businesses lose capital, in order to fix these problems we need solutions.

These examples are illustrative as they use some of the terms belonging to the domain of machines which facilitate the understanding of economic phenomena.

Going back to our former example, "Economy is a car not a body", we may interpret it differently if we take into consideration that both cars and human bodies are part of the source domain which may also be seen as containers. An abstract complex system such as Economy may be metaphorically conceptualized in terms of a body, the body of a person. This is possible because the human body is a powerful centre of metaphorical expansion. The body serves here as a container and may also function as a donor domain. The idea of a human body seen as a container with a bounding surface and an in-out orientation belongs to Lakoff who states that not only objects but substances as well can be viewed as containers. Firms, trade unions, or even the Economic system itself may be seen as Economic body. (George Lakoff and Mark Johnson, 1980)

In the conceptual metaphor ECONOMY IS A BODY/ A HUMAN BEING, the individuals anthropomorphize economic activities. In other words, through anthropomorphic metaphors, the transfers of meaning take place from the human body and its parts, and from human senses and human passions to inanimate objects. But, anthropomorphic metaphors may also draw comparisons to the psychology of the human mind. In this case, economy can disappoint societies, may suffer exactly like individuals, or may recover from crisis. In anthropomorphic metaphors, the parts of the body are metaphorically used to describe different aspects of Economy. We consider that the following examples speak for themselves: 
Economic depressions: cause and cures. (BNC) (It is possible for Economy to collapse due to external causes. The same way people feel depressed and cannot recover without help.)

These are the permanent scars of recession. (BNC) (Recessions generally occur when there is a widespread drop in spending. This process usually leaves signs.)

The heart of dynamic economy beats strong. (BNC) (The heart is considered the most important part of a body; Economy is associated with living organisms.)

In capitalism, money is the life blood of society but charity is the soul. (The streams of money flow in and out exactly like blood passes through our vessels.) This is also an example of a liquid metaphor that we will also discuss later, in this paper.

Economic performance in 1989 showed a great improvement as a result of recoveries in the sugar and tourism industries, the backbone of the economy. (BNC) (the backbone supports the body.)

The US Economy is back on its feet again. (BNC) (Economy has recovered.)

Persons like Caliban have no head for money. (BNC) (Without a brain we cannot reason.)

We didn't have any supplies on hand and were unable to finish the job. (on hand, meaning in one's possession).

The new manager has his finger in the pie of many small businesses. (to be involved in something, to receive money for something).

The small computer company went belly up several months ago. (to go out of business because of financial problems.)

According to the cognitive perspective, some types of metaphors allow us to orient concepts, refer to them, and quantify, etc., them, as we do with some orientational and ontological metaphors. In the example above, the metaphoric expression went belly up also functions as an orientational metaphor.

Orientational metaphors, as their name states, give concepts a spatial orientation. They are metaphors in which concepts are spatially related to each other, as in the following ways: up and down, in and out, front and back, on and off, deep or shallow, central or peripheral. In each case, the target concepts are paired the way the source concepts are: antonymous or counterparts. In our investigation we have encountered metaphoric expressions belonging to the conceptual metaphor ECONOMY IS PLANT. Words from the source domain of plant are used metaphorically to describe aspects of Economy. The most commonly used items are flourish, weed out, spread, growth, to put down to roots, to soar, to blossom, etc. Knowledge about plants trees, flowers, fruit and vegetables are very accessible to people and contribute to the understanding of economy.

The examples selected from the British National Corpus are illustrative for this type and speak for themselves.

The new business has started to put down roots.

Grow your money tree by planting money seeds.

The best way to allow an economy to flourish is to stand back and give room for choice, competition, incentive and the will to succeed.

It is spreading to other firms too, as banks weed out their client lists in order to raise profits and cut asset growth.

Profit is soaring.

The entire company grew from one simple idea.

Healthy diet, healthy environment with a fruitful economy!

The Firm blossomed into a major real estate player.

Up to know, we have seen that Economy can be a machine/ a mechanism/ an object, a body, a plant. We have also found evidence of the conceptual metaphor Economy is a SUBSTANCE/ A SOLID OR A LIQUID. MONEY IS FOOD is another illustrative example of conceptual metaphor of the type A is B. Every person is said to lead a 
hand-to-mouth existence, although this expression is more often used for the person in the first situation, the one who must put whatever food comes into his/her hand into his/her mouth immediately in order to survive. People in this condition are living from meal to meal by necessity, not by choice. Some linguistic instantiations of the conceptual metaphor can be expressed as: MONEY IS FOOD. When people cook the books it is said that they keep false accounts to make money illegally or avoid paying taxes. All the tea in China may be used to refer to honest people that wouldn't do anything not even for a large sum of money. Dough is used to refer to cash and other financial assets. The connection between dough and money may not be apparent taking into consideration that in baking, dough is too rigid to leak but flexible enough to knead. Another possibility is to take into consideration the metaphor to be rolling in dough which suggests the existence of a large sum of money, more than needed. When somebody skims the profits, it means that one hides earnings or profits in order to avoid paying taxes on them. Passing from dough to cakes, the expression to have a cake and eat it refers to a person who wants a well-paid secure job, without working evenings or weekends. Be your bread and butter refers to an activity or job that somebody does in order to get the money he needs. The metaphor a person selects to frame a concept focuses attention on some aspects but ignores others. For example, in considering food "a commodity" people's attention draws on commerce, on anything that can be marketed: bought or sold. Expressions such as he won't buy that or the idea won't sell emphasize how ideas, viewed as food products can be intellectually marketed. Through such familiar examples, abstract or complex concepts can be easily understood.

Not only food may be seen as a commodity but ideas also, the way we package our ideas or ideas that won't sell. There are always marketing ideas to boost our business. That's a worthless idea. These are only some examples of metaphorical expressions offering guidance into a metaphorical world. When metaphoric expressions have associated conventional images, it is common for an independently motivated conceptual metaphor to map that knowledge from the source to the target domain.

When talking about leadership and budget, the following examples speak for themselves: He is the big cheese, where the big cheese is "the boss;" he/she is the breadwinner in the family used "to portray the person who earns the most money," here food is about gender. Bean counter stands for the job of accountant in the example "He had been working as a bean counter for 20 years before he resigned."(BNC)

MONEY IS FOOD is a familiar example of a structural metaphor, as it provides understanding of one concept in terms of another. Money is referred to as dough, bread and bacon. In the example He brings home the bacon, bacon is used to refer to the amount of money that family lives on. We conceptualize a lot of abstract and less delineated domains in terms of domains that are relatively better understood and more delineated in our physical and cultural environments. A metaphor involves cross-domain mappings: the source (more delineated) domain is mapped onto the target (less delineated) domain, and these metaphorical mappings are experientially grounded.

With the conceptual metaphor MONEY IS LIQUID, we talk about liquid assets, liquidity, liquidation, cash flow, outflow, currency. Economists use the term liquidity for money because banks act like tanks of water; thus, banks become a kind of reservoirs with streams of money flowing in and out. Many examples of metaphoric expressions belonging to the conceptual metaphor MONEY IS LIQUID may also be classified as orientational, because money flows in and out. Another illustrative example: Funds rush to pour money into online lending. (BNC)

The expression cash flow also shares similar characteristics to water flow. There are plenty of metaphorical examples which highlight the similarity between cash and liquid. Liquidity equates convertibility. Cash is highly liquid because one can convert it to almost anything (from cars to household appliances, houses and real estates, land, firms, etc.) in a very short period of time. 
Alternatively, non-liquid assets can't be converted from one form to another.

The fact that banks hold a number of fairly liquid assets, such as money at call, bills of exchange and short-dated bonds, makes it difficult to identify a simple liquidity ratio. Liquid asset refers to the money that a company or a person has, and the property they can easily exchange for money. As a metaphor, money acquires the attributes of a liquid, a wet substance which flows, has no fix shape and can be easily exchanged or sold to pay debts. With liquidity risk, it should be recognised that diversification into new areas of business may reduce the ability of institutions to obtain liquid funds.

There are plenty of metaphorical examples in the field of Economics which highlight the similarity between cash and liquid. (BNC) We find the following examples illustrative for our investigation.

The problem with a high-tech start-up is that you have a net cash outflow. (BNC)

'A number of victims have already gone into liquidation,' he added. (BNC)

One member asked for details of how my father had gone into voluntary liquidation. (BNC)

Mundie, one of the three founders of Alliant in 1982, will remain on the board to advice in final sale of the service business and ultimate liquidation of the company. (BNC)

The fact that banks hold a number of fairly liquid assets, such as money at call, bills of exchange and short-dated bonds, makes it difficult to identify a simple liquidity ratio. Many of these terms have been accepted by the English speakers and are known as lexical metaphors.

Somebody who is without debt is called solvent. A solvent business is a company that lacks liquidity. A rich person is called affluent. In affluent suburbs wealthy people have large houses and tree-lined streets.

Affluent workers remain, in spite of their affluence, men who live by selling their labour power to their employers in return for wages.

In an Affluent society the material benefits of prosperity are widely available.

Spending money is also like moving a liquid. When somebody invests money in something, they prim/pour the pump, sink, inject money into it, or drain.

"If several big bills fall due when you first start you may have to "prime the

pump' with savings".

In the late 1800s this expression originally was used for pouring liquid into a pump to expel the air and make it work. In the 1930s it was applied to government efforts to stimulate the economy and thereafter was applied to other undertakings. (Dictionary http://idioms.thefreedictionary.com/prime+the+pu mp, accessed on 20 March 2015)

Arriving as ostentatiously as you'd expect from the seriously wealthy, business angels pump money into private companies in return for shares. (BNC)

Our investigation continues with other examples of liquid metaphors which refer to causing (a resource or supply of something) to be used up gradually and often completely, the same as we draw off (a liquid) by a gradual process.

As an election approaches, the government of the day will pump money into the economy. (BNC)

The mining industry has predicted that the ban will have dire economic consequences, forcing the loss of hundreds of jobs and forcing investors to sink funds into overseas mining ventures. (BNC)

Why does Guinness sink money into an elephant reserve in Kenya and J. Sainsbury splash out on a dolphin patrol in the Far East? (BNC) 
If it is likely that the Purchaser has to inject money into the business it could end up losing more than it paid if there is a total disaster and the Vendor's liability is limited in this way.

We pull the plug on it when we stop supporting something financially. (BNC)

The government pulled the plug on spending (BNC) (to prevent from happening or continuing, to stop spending money on something.)

Mr O'Hare suspects that 'not that many [profit sharing schemes] have been put in place over the last couple of years' because of the cash flow drain represented by the company's contributions to the fund. (BNC)

Just less than half the money created went down that drain. In the immediate post-war period Germany constituted the single most important drain on the dollar. (BNC)

If there's a lot of money floating about in this area then I think that, some committee or other should be looking at the refurbishment of the courts which are a disgrace. (BNC)

In this category of conceptual metaphors proved to be the most flourishing. Here, we have also identified examples of hyperboles, figures of speech based on the exaggeration used for the sake of emphasis:

Money poured into the market after the thin pre-election trading. (BNC)

The high interest rates offered made funds flood into our bank. (BNC)

An extra $£ 2$ billion flooded into the market as the top 100 share index rose by over 13 points. (BNC)

America's banking troubles have also brought in business: Swiss banks have been flooded both with deposits and loan requests from blue-chip American firms. (BNC)

As we have observed, metaphor is perceived as involving processes of conceptual blending in which the target is understood in terms of the source. Liquid, as the source domain constitutes the framework for the target domain determining the ways in which the target domains refer, and the ways we act, as in the case of money. Only some of the particular features of the literal meaning of the source domain (vehicle) are being transferred to the target domain (topic). The relationship between the literal and metaphorical meanings or the grounds is responsible for the way metaphor works. For example, a typical feature in the target domain LIQUID, a substance which exhibits a characteristic readiness to flow and little or no tendency to disperse, and is amorphous but has a fixed volume and is difficult to compress. At the same time, exactly as water, it is a nutrient that sustains life/ a liquid necessary for the life of most animals and plants. MONEY IS LIQUID is an ontological metaphor which gives shape to abstract concepts and helps us, conceptualise them as objects. Money is what we earn by working and what we spend in order to buy things. Money is the most liquid asset of all because it is the most common medium of exchange; it does not have to be converted into anything else in order to make purchases. MONEY IS LIQUID is an ontological metaphor which gives shape to abstract concepts and helps us, conceptualise them as objects. Money is what we earn by working and what we spend in order to buy things. Money is the most liquid asset of all because it is the most common medium of exchange; it does not have to be converted into anything else in order to make purchases. As our investigation shows, the field of Economics can play the role of the source domain which can be used for the concept area from which metaphor is drawn. It is interesting to note that not all the aspects of the source necessarily map onto the target but only the prototypical features. 
Nevertheless, similarities derive from correlations and the grounds bases on them. Unfortunately, some of the metaphors are so often used that one is unaware of their metaphoric meanings and they stop being perceived as metaphors and become conventionalised expressions.

\section{Conclusions}

This paper demonstrates the pervasiveness of metaphors in everyday language and its capability of creating new realities. Metaphorical expressions can offer people guidance into a metaphorical world in which concepts lead them on an organised path of daily activities. When metaphoric expressions have associated conventional images, it is common for an independently motivated conceptual metaphor to map that knowledge from the source to the target domain.

The Economic domain is available for anyone who wishes to take a well-understood aspect from a familiar domain and use it in such a way as to stand for a thing as a whole or just for a part of it. The cognitive approach proved to be relevant for the research; metaphors offer a variety of the interpretative use of language and give rise to semantic extension.

\section{References}

Andrioai, G. (2009), Conceptual Metaphors Based on Food Idioms, Proceedings of the 2nd ROASS Conference, Transmodernity. Managing Global Communication, Alma Mater Publishing House, Bacău, pp. 505 - 517.

Andrioai, G. (2009), A Cognitive Approach to Metonyms Based on Food, Interstudia. Semestrial Review of the Interdisciplinary Centre for Studies of Contemporary Discursive Forms, Volume Language, Discourse, Society, Nr. 3, Ed. Alma Mater, Bacău, pp. 109-118.

Andrioai, G. (2009), Metaphors and Metonyms Are Not Mere Words. A Food-Based Analysis on Conceptual Metaphors and Metonyms, Style In Language, Discourses and Literature, V, Horia Hulban (Editor), Lumen, Iaşi, pp. 91-103.

Avãdanei, Ş. (1994), La început a fost metafora..., Editura Virginia, Iaşi.

Hulban, H.(Editor) (2005) Metaphorical Models, Style in Language, Discourses and Literature I, Lumen, Iaşi.

Hulban, H. (2001), Syntheses in English Lexicology and Semantics, Ed. Spanda, Iaşi. Lakoff, G., Johnson, M., (1980) Metaphors We Live By, University of Chicago Press.

Neagu, M., (2005), Cognitive Linguistics. An Introduction, Editura Didactica şi Pedagogică R.A., Bucureşti.

Ricoeur, P., (1977), The Rule of Metaphor. Multi-Disciplinary Studies of the Creation of Meaning in Language, Translated by Robert Czerny with Kathleen McLaughlin and John Costello, SJ, Routledge \& Kegan Paul, English Translation, University of Toronto Press.

Ullmann, S., (1967), The Principles of Semantics, Basil Blackwell, Oxford. 